\title{
INITIATION AND PROPAGATION OF SHORT FATIGUE CRACKS IN A WELD METAL
}

\author{
Hong Youshi, Lu Yonghua and Zheng Zhemin (C. M. Cheng) \\ Institute of Mechanics, Academia Sinica, Beijing, China
}

(Received in final form 21 Nonember 1988)

\begin{abstract}
Fatigue tests were performed using a purpose designed triangular shaped specimen to investigate the initiation and propagation of short fatigue cracks in a weld metal. It was observed that short fatigue cracks evolved from slip bands and were predominantly within ferrite grains. As the test progressed, the short crack density increased with minor changes in crack length. The growth of short cracks, in the early stage resulted mainly from coalescence with other existing cracks. The mechanism of short crack behaviour is discussed.
\end{abstract}

\section{NOMENCLATURE}

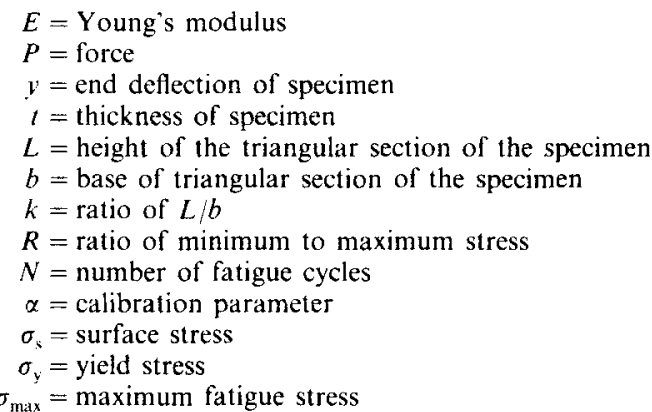

\section{INTRODUCTION}

The behaviour of short fatigue cracks in metals and alloys has attracted considerable attention, both because the initiation and propagation of short cracks are the early and important damage stages of fatigue failure and because such behaviour cannot be fully explained by conventional fracture mechanics theories. The problem of short fatigue cracks and recent progress have been reviewed by Miller [1, 2], Smith [3] and Suresh and Ritchie [4].

It is widely recognized that the processes of short fatigue crack initiation and propagation are significantly influenced by the microstructure of metals and alloys. For example, Kunio et al. [5] demonstrated that, in a martensitic steel, short fatigue cracks initiated at inclusions and grew along the martensite plate or packet boundary. In Al 7075-T6 and A1 2219-T851, Lankford [6] and Morris [7] observed that short fatigue cracks nucleated at small inclusions such as brittle intermetallic particles.

In the present study, weld metal and a purpose designed triangular shaped specimen cut from the weld were used to investigate the initiation and propagation characteristics of short fatigue cracks. The correlation between the short crack behaviour and the weld microstructure was examined and discussed. 


\section{EXPERIMENTAL PROCEDURE}

\section{Material and specimen}

Plates of $30 \mathrm{~mm}$ thick mild steel $(0.18 \% \mathrm{C})$ were welded from both sides by manual submerged arc welding. The weld section is schematically shown in Fig. 1(a). The specimen blanks, cut from the weld plate, were austenitized at $925^{\circ} \mathrm{C}$ and then air cooled to normalize the microstructure and eliminate residual stresses produced in welding. This is to obtain a test material of mild steel with equiaxed inclusions. The chemical composition of the weld section (by wt $\%$ ) is $\mathrm{C}-0.12, \mathrm{Si}-0.55$, $\mathrm{Mn}-0.97, \mathrm{P}-0.025, \mathrm{~S}-0.012, \mathrm{O}-0.032, \mathrm{~N}-0.011$, and the remainder Fe. The yield stress, measured by uniaxal tensile testing using cylindrical bars cut in the longitudinal direction of the weld, is $310 \mathrm{MPa}$.

The triangular shaped specimens were purpose designed [Fig. 1(b)], so that, when the specimen is subjected to an end flexural loading, within the isosceles triangular part of the specimen, the tensile surface stress is constant for a given deflection. A large specimen area for investigating the fatigue deformation and damage characteristics at a given stress level is therefore available. These
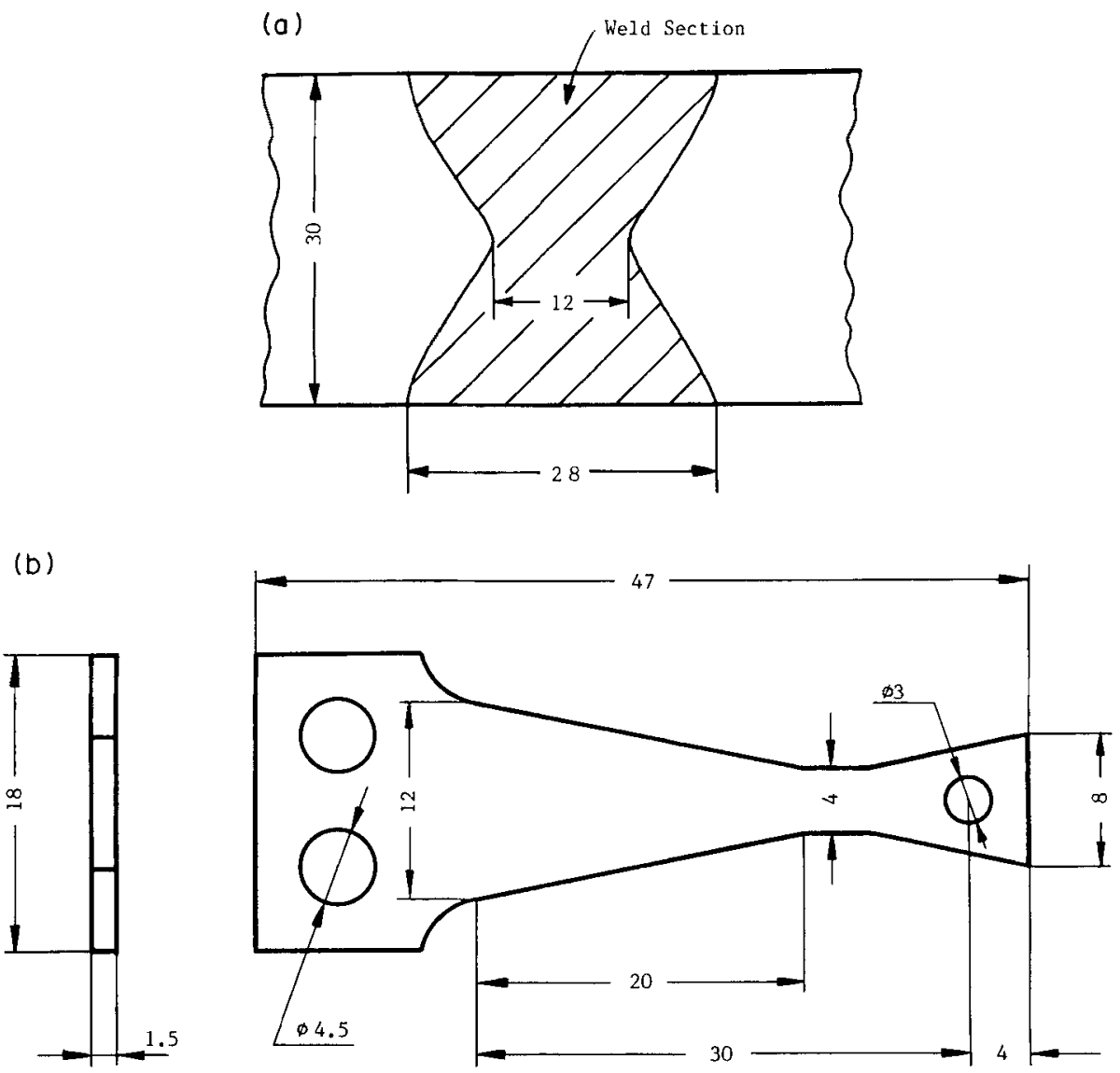

Fig. 1. (a) Schematic of weld section, welding direction normal to this page (dimensions in $\mathrm{mm}$ ).

(b) Schematic of triangular shaped specimen (dimensions in $\mathrm{mm}$ ). 
specimens were also cut in the longitudinal direction of the weld to the designed size by electric spark erosion and care was taken to make sure that the triangular part of each specimen is within the weld section. Both surfaces of the specimen were ground and polished to a finish of $0.5 \mu \mathrm{m}$. Some polished specimens were etched to reveal the microstructure. The average percentage of pearlite is $16 \%$ and the average ferrite grain size is $22 \mu \mathrm{m}$; both measured from optical microscope photos.

\section{Fatigue test}

Testing was carried out on a fatigue machine at room temperature. The wider end of the specimen was clamped in an appropriate support and the other end was connected to the vibration machine through a pliable bar to permit free displacement in the longitudinal direction of the specimen. The constant surface stress within the triangular part of the specimen is given by

$$
\sigma_{\mathrm{s}}=\frac{6 k p}{t^{2}}
$$

From both calculations and calibration, the relation between bending end deflection and loading was established. We obtained

$$
\sigma_{\mathrm{s}}=\alpha \frac{E t y}{L^{2}}
$$

where the parameter, $\alpha$ is used to allow for the shape not conforming to the triangle near the loading end; its value is 1.04 . Therefore, a given end deflection yields a constant surface stress in the triangular section of the specimen. The specimens were fatigued at a frequency between 10 and $12 \mathrm{~Hz}$ for $R=-1$ and $\sigma_{\max }=0.8-1.2 \sigma_{\mathrm{y}}$. The maximum number of cycles was $1,000,000$.

\section{Ohservations}

Tests were interrupted at set intervals depending on the applied stress level. Between intervals, the specimen was removed from the test rig and observed under an optical microscope using polarized illumination. After examination, the specimen was put back in the machine and the same fatigue loading was again applied. Sites for future observations were selected and hard copy records taken of the initiation and growth of short cracks.

\section{RESULTS AND DISCUSSIONS}

\section{Initiation of short fatigue cracks}

After the first few thousand cycles of fatigue loading at the stress level of $\sigma_{\max }=0.9 \sigma_{\mathrm{y}}$, it was observed that a few isolated creases, i.e. slip bands, appeared on the surface of pre-polished but unetched specimens [Fig. 2(a)]. Further testing induced the formation of additional new slip bands and intensified the previous ones which led to the gradual formation of slip steps [Fig. 2(b) and (c)]. The heavily developed slip bands displayed the next phenomena of so-called extrusions and intrusions which eventually evolved into surface short cracks [Fig. 2(d)]. After $N=100,000$ at $\sigma_{\max }=0.9 \sigma_{\mathrm{y}}$ the specimen was etched. It revealed that most short cracks initiated within ferrite grains and only a few were associated with grain boundaries. Figures 3 and 4 show, for instance, that several short cracks initiated in ferrite grains (Fig. 3), with a few close to grain boundaries (Fig. 4). Since the short cracks originated from slip deformation, it is understandable that they formed within the grain. For cracks formed at grain boundaries, it is assumed that slip bands were in operation very close to a relevant grain boundary. 

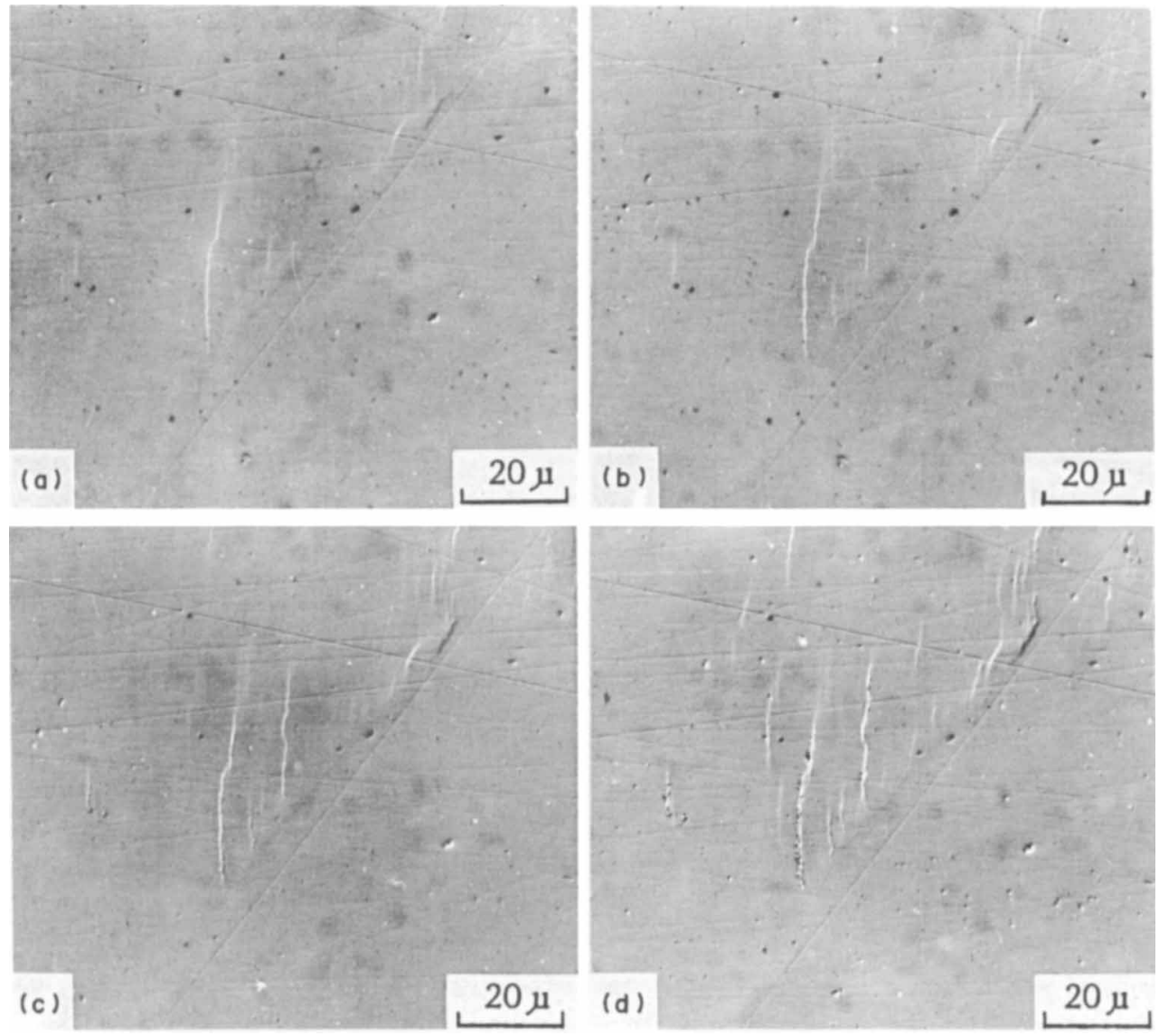

Fig. 2. Photos of the same field taken to show the initiation of short fatigue cracks on an unetched specimen at $\sigma_{\max }=0.9 \sigma_{y}$ (transverse axis parallel to tensile stress). (a) $N=2000$; (b) $N=5000$; (c) $N=10,000$; (d) $N=20,000$.

At the stress level $\sigma_{\max }=1.1-1.2 \sigma_{y}$, isolated short cracks can be found in ferrite grains, after only 2,000 cycles of fatigue loading, as shown in Fig. 5(b) taken from a pre-etched specimen. The number of short cracks distributed in ferrite domains increased with further cycling [Fig. 5(c-h)]. At this stage and stress level, short crack lengths were between 10 and $30 \mu \mathrm{m}$. Some of them terminated with one or both ends at grain boundaries [Fig. 5(b-h)]. In other words, the length of a short crack is associated with the size of the ferrite grain in which it is located, and the corresponding grain diameter is the maximum length for short crack before coalescense. For a short crack to arrest wholly within a ferrite grain suggests that it may have reached a sub-boundary or other intragranular obstacles.

Large differences in the microhardness values of ferrite and pearlite give an idea of the propensity of each constituent to initiate cracks. Ferrite being much softer, $(153 \mathrm{Hv}$ as compared to $220 \mathrm{Hv}$ for the pearlite), is more prone to deformation by slip and therefore more prone to cracking.

The orientation of earlier formed short cracks tends to be perpendicular to the surface tensile stress, while later cracks lie in directions gradually deviating from the axis perpendicular to the 

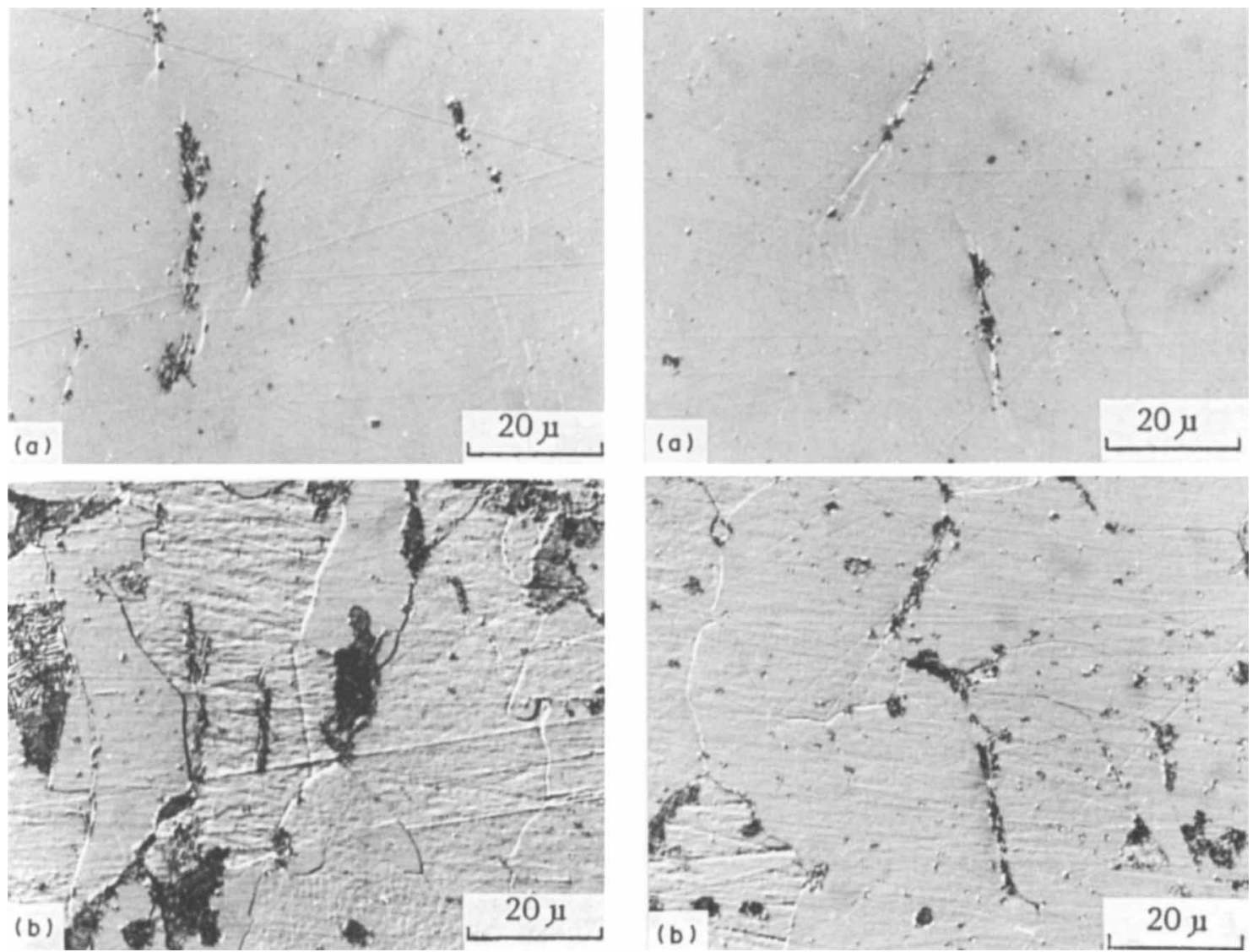

Fig. 3. Short fatigue cracks formed in the interior of ferrite grains at $\sigma_{\max }=0.9 \sigma_{\mathrm{y}}$ and $N=100,000$ (transverse axis parallel to tensile stress). (a) Unetched; (b) same field as

Fig. 4. Short fatigue cracks formed close to grain boundaries at $\sigma_{\operatorname{mix}}=0.9 \sigma_{y}$ and $N=100,000$ (transverse axis parallel to tensile stress). (a) Unetched; (b) same field as (a) but etched. (a) but etched.

tensile stress. The range of distribution of the angle between cracks and the tensile stress is between 90 and $45^{\circ}$ (Figs. 2 and 5).

Even though a specimen has been fatigued for more than $10^{5}$ cycles at $\sigma_{\max }=1.2 \sigma_{y}$, and short cracks have become densely distributed in many ferrite grains, a small fraction of ferrite grains remains undamaged, not a single short crack initiates in such grains [Fig. 5(h)]. This implies that the initiation of short cracks is very sensitive to the crystalline orientation of ferrite grains. For ferrite grains where early short cracks initiate, the Schmid factor of the potential slip system is relatively large so that this system can be easily activated, whereas for ferrite grains without short cracks after $10^{5}$ loading cycles, the Schmid factor concerned is too small to make the slip system operative. These observations also indicate that short fatigue cracks in this material, show no preference to initiate at inclusions.

\section{Propagation of short fatigue cracks}

Short cracks grow almost unimpeded within the ferrite grain until they reach the grain boundary at one or both ends. The growth of these cracks is then halted and they become non-propagating cracks, with their length determined by the grain size. 

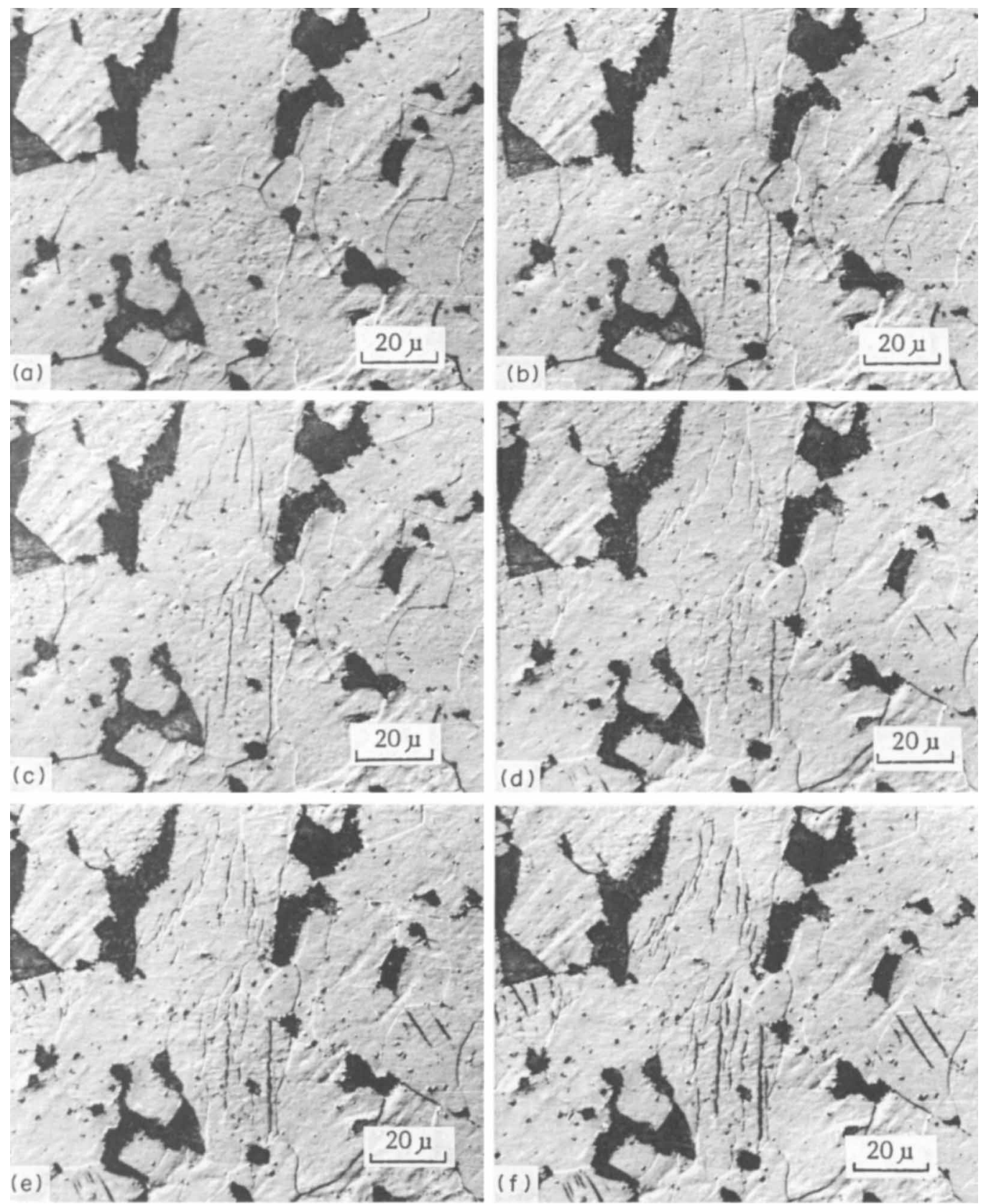

Fig. 5. (a-f) Caption on facing page. 

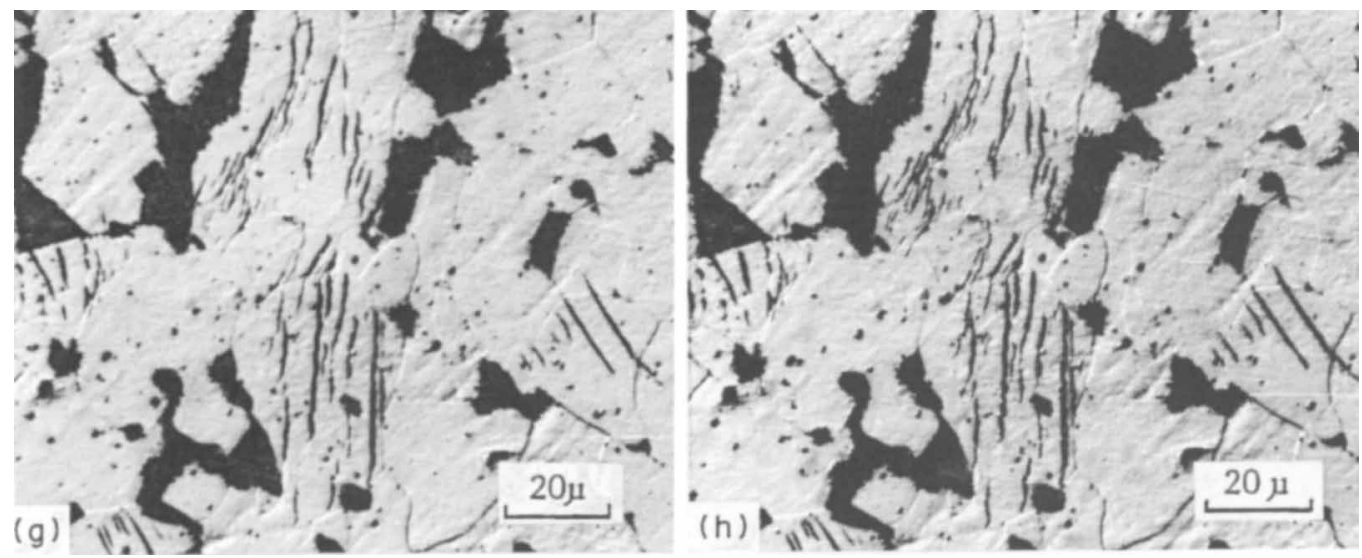

Fig. 5. Photos of the same field to show the development of short fatigue cracks on an etched specimen at $\sigma_{\max }=1.2 \sigma_{y}$ (transverse axis parallel to tensile stress). (a) $N=0 ;$ (b) $N=2,000 ;$ (c) $N=6,000$; (d) $N=14,000$; (e) $N=30,000$; (f) $N=61,000$; (g) $N=101,000$; (h) $N=127,000$.

As mentioned earlier, the density of short cracks gradually increases with fatigue cycles. The propagation of short cracks of fixed length proceeds through coalescence with nearby short cracks. It appears that, coalescence takes place when the short crack density approaches a critical value. At this stage, a few main cracks, each with a length of several grain sizes, can be sporadically formed. Such main cracks lead to the final failure of the specimen. Figure 6 shows such a crack that crosses more than three ferrite grains after 127,000 cycles at $\sigma_{\max }=1.2 \sigma_{y}$. At the beginning of short crack coalescence, the crack path is transgranular (Fig. 6). The propagation of a main crack is caused not only by gradual growth but also by coalescing with other cracks which are suitably orientated. In the present case, when most main cracks propagated through about 10 or more grains, the main cracks coalesce, which leads to the formation of a dominant crack and final fracture. Figure 7 shows the coalescence of main cracks. A suitably orientated short crack between two main cracks can act as a bridge to connect the two, making crack path transgranular (mark

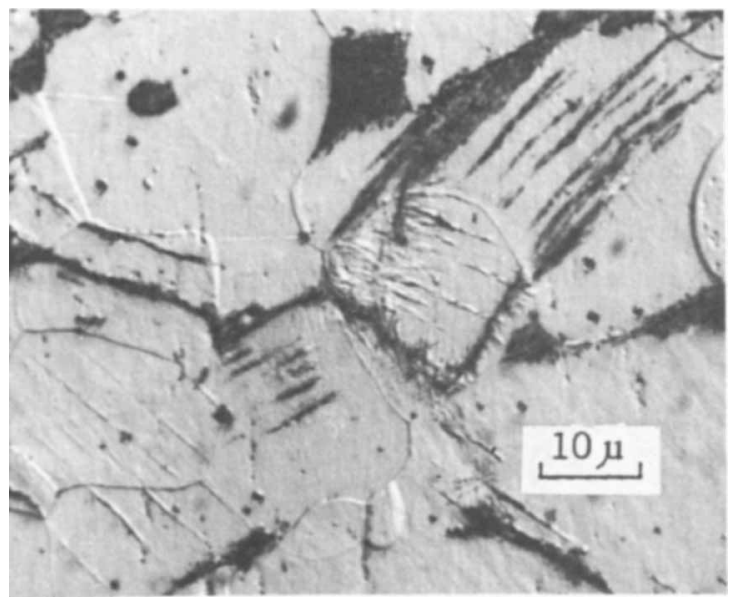

Fig. 6. A main crack across several ferrite grains at $\sigma_{\max }=1.2 \sigma_{y}$ and $N=127,000$ (vertica) axis parallel to tensile stress) 

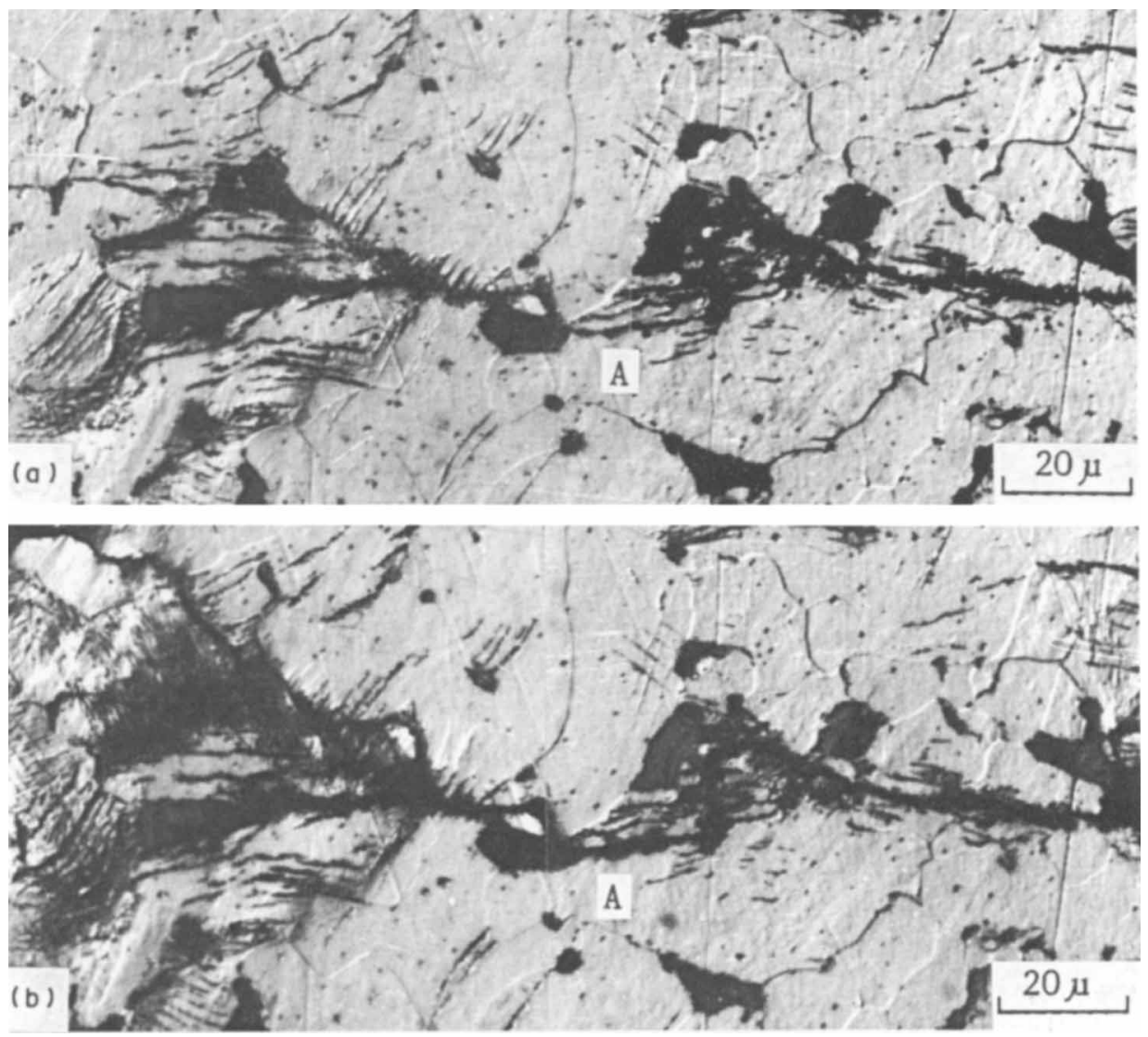

Fig. 7. Propagation of a main crack at $\sigma_{\max }=1.2 \sigma_{\mathrm{y}}$ (vertical axis parallel to tensile stress). (a) $\mathrm{N}=101,000$; (b) $N=127,000$.

A in Fig. 7). Otherwise the crack propagation path may be either transgranular or intergranular (Fig. 7).

As discussed earlier, throughout the test the number of short cracks increases and the coalescence between short cracks brings about accelerated crack propagation. Therefore, it is difficult to define and measure the crack length during the stages of propagation. Instead, a combination of crack density and average length may be an effective parameter to describe the early development of short fatigue cracks. However, when a main crack forms and before it merges with others, the crack growth may be measured.

\section{CONCLUSIONS}

From our investigation, the following conclusions can be drawn.

1. Short fatigue cracks initiate predominantly within ferrite grains and the initiation originates from slip bands. The ferrite grain size is a controlling microstructural feature for short fatigue crack behaviour. 
2. The development of short cracks in the early stages is marked by the increase in the number of short cracks with fatigue cycles, whereas the length of most short cracks undergoes little change.

3. The propagation of a short crack is attributed to its coalescence with others to form main cracks. The merging of main cracks results in the final fracture of a specimen.

4. The path of a short crack is transgranular during its early stage. The path for a growing main crack may be transgranular or intergranular depending on the characteristics of the neighbouring short cracks.

Acknowledgement-This paper is supported by the Chinese Academy of Sciences under Special Grant No. 87-052.

\section{REFERENCES}

1. Miller K. J. (1982) The short crack problem. Fatigue Engng Mater. Struct. 5, 223-232.

2. Miller K. J. (1987) The behaviour of short fatigue cracks and their initiation: Part II-a general summary. Fatigue Fract. Engng. Mater. Struct. 10, 93-113.

3. Smith R. A. (1983) Short fatigue cracks. Fatigue Mechanisms: Advances in Quantitative Measurement of Physical Damage, ASTM STP 811 (Edited by Lankford J., Davidson D. L. Morris W. L. and Wei R. P.), pp. 264279.

4. Suresh S. and Ritchie R. O. (1984) Propagation of short fatigue cracks. Int. Metall. Rev. 29, 445-476.

5. Kunio T., Shimizu M., Yamada K., Sakura K. and Yamamoto T. (1981) The early stages of fatigue crack growth in martensitic steel. Int. J. Fract. 17, 111-119.

6. Lankford J. (1982) The growth of small fatigue cracks in 7076-T6 Aluminum. Fatigue Engng Mater. Struct. 5, 233-248.

7. Morris W. L. (1979) Microcrack closure phenomena for Al 2219-T851. Metall. Trans. 10A, 5-11. 